\title{
Sending Learning Pills to Mobile Devices in Class to Enhance Student Performance and Motivation in Network Services Configuration Courses
}

\author{
Mario Muñoz-Organero, Member, IEEE, Pedro J. Muñoz-Merino, Member, IEEE, and \\ Carlos Delgado Kloos, Senior Member, IEEE
}

\begin{abstract}
Teaching electrical and computer software engineers how to configure network services normally requires the detailed presentation of many configuration commands and their numerous parameters. Students tend to find it difficult to maintain acceptable levels of motivation. In many cases, this results in their not attending classes and not dedicating enough time to acquire the required competencies. This paper describes a successful experiment that was able to improve student class attendance, performance, and motivational patterns by using mobile devices in class to provide students with contextualized learning pills. A learning pill is a simple exercise that summarizes some of the key concepts explained in class and promotes reflection and self-study. Each student attending a particular lecture or laboratory session automatically receives a learning pill on his or her mobile phone just after the related concept has been presented. This paper details the scenario used in the experiment and analyzes the performance and motivational patterns of 170 students at the Higher Polytechnic School, Carlos III University of Madrid, Leganes, Spain.
\end{abstract}

Index Terms-Educational technology, higher education, learning systems, pattern recognition, prediction methods, student experiments.

\section{INTRODUCTION}

$\mathbf{T}$ HE QUEST to motivate students and to promote the acquisition of relevant competencies in engineering studies is challenged by the proliferation of information, multidisciplinary technological development, globalization, social responsibility, participatory corporate structures, and rapid change [1]. Engineering students need to develop competencies having three main components: knowledge, the skills they use in managing and applying that knowledge, and their attitudes that dictate to which goals their knowledge and skills will be directed [1]. Using mobile devices to create pervasive learning systems and provide contextualized information to students, if used in properly designed environments [2], can promote the better assimilation of knowledge and development of skills

Manuscript received February 09, 2011; revised March 02, 2011; accepted March 11, 2011. This work was supported by the ARTEMISA project TIN200914378-C02-02 within the Spanish "Plan Nacional de I+D+I" and the Madrid regional community projects S2009/TIC-1650 and CCG10-UC3M/TIC-4992.

The authors are with the Carlos III of Madrid University, 28911 Leganes, Spain (e-mails: munozm@it.uc3m.es; pedmume@it.uc3m.es; cdk@it.uc3m.es).

Color versions of one or more of the figures in this paper are available online at http://ieeexplore.ieee.org.

Digital Object Identifier 10.1109/TE.2011.2131652 by facilitating the interaction between teachers and students, supporting awareness and understanding of the student context, and intuitively supporting proactivity and availability [3]. This paper presents the results of the deployment of a proactive and contextualized system that, in class, sends concise exercises (learning pills) to the students' mobile devices; these exercises summarize key concepts just explained by the professor and promote reflection and self-study. The paper analyzes data from 170 students who were learning how to properly configure some of the services in an IP network using a Linux environment of servers. The paper studies the motivational impact upon students and their learning outcomes and compares the patterns and results of those students in the course who chose to receive and use the learning pills to those who did not.

The rest of this paper is organized as follows. Section II reviews some of the major previous studies of learning with mobile devices and student motivation. Section III describes the e-learning scenario in which the experiment was conducted. Section IV details the process of learning from the learning pills. Section $\mathrm{V}$ analyzes the results in terms of the improvement in the number of students attending more than half of the course lectures, their learning results, and the evolution of their motivation patterns. Finally, conclusions are summarized in Section VI.

\section{Learning With Mobile Devices AND Motivation OF STUDENTS}

The omnipresence of mobile personal devices among students, together with the steady improvement of these devices' computational and networking capabilities, is leveraging the definition, creation, development, and deployment of new m-learning architectures and environments. Ogata [4] describes the design of a computer-supported ubiquitous learning environment for teaching languages. Wu et al. [5] define a context-aware ubiquitous learning environment that uses mobile devices, sensors, and wireless networks to conduct situated learning. Thomas [6] presents a theoretical model of the pervasive learning space and of pervasive learning that can be used to help design, develop, and evaluate pervasive learning experiences. Keil-Slawik et al. [7] illustrate the use of learning objects in distributed knowledge spaces, a key concept for building up pervasive learning environments. Syvanen et al. [8] reflect on the importance of context awareness and adaptivity for supporting pervasive learning environments. Kajita et al. [9] describe a ubiquitous computing environment (uClassroom) that makes use of context to provide optimized educational information. Kim [10] presents a ubiquitous smart classroom 
environment called uClass that combines teaching methodologies and learning resources from homes, schools, and communities through a ubiquitous, interactive network. Jones and Jo [11] developed a ubiquitous learning environment (ULE) as an adaptive teaching system using ubiquitous technologies. Scott and Benlamri [12] define an architecture for learning spaces supported by the use of mobile devices that can seamlessly adapt to formal and informal learning scenarios.

Several studies, such as [13] and [14], have analyzed the implications of the use of mobile devices for learning and the effects on student motivation and performance. Academic performance and successful completion of studies depend on many factors [15], [16]; particularly important among these are student motivation and student self-confidence in succeeding [17]. Educational researchers distinguish between intrinsic and extrinsic motivation [18]. Intrinsic motivation is related to the interest, curiosity, and enjoyment that a task causes in the student, while extrinsic motivation measures the engagement of a student because of a reward or punishment from an external source or because of a positive mental attitude to perform a task either by itself or in a context. Self-determination theory [19] provides a further division of extrinsic motivation into four categories that vary according to the level of self-determination, which reflects the aspect of quality of motivation: external regulation, introjected regulation, identified regulation, and integrated regulation. External and introjected regulations can be grouped in a controlled motivational profile, while identified and integrated motivations define more autonomous types of motivation [20].

Student motivation states change with time during the teaching of a course [21]. The initial enthusiasm at the beginning of the course tends to have a positive impact on the student's motivation, while the effort required to acquire the knowledge and associated skills and attitudes negatively impacts the levels of student motivation as the course advances. This effort is somehow compensated toward the end of the course by the self-confidence that students acquire as they master the various parts of the course contents.

The study presented in this paper analyzes the motivation time patterns of electrical engineering students in a network services configuration course and the positive impact of their using mobile devices to receive learning pills in class. The students' motivation levels are measured using a questionnaire at three different points during the course: at the beginning, toward the middle, and near the end of the course. The questionnaire contains motivation-related questions measuring intrinsic and extrinsic motivational aspects (guided both by controlled and autonomous motivational profiles) in a Likert-type scale [22]. The influence on the motivational impact and on the learning outcomes is compared for those students in the course who chose to receive and use the learning pills and those who did not. The rate of students attending classes in the offering of the course applying learning pills is also compared to the rate of attendance in the previous offerings in which no learning pills were available.

\section{IMPLEMENTED SCENARIO}

The experience of teaching the configuration of network services to 120 electrical and computer software engineers over three different offerings (2007-2009) of the "Advanced
Network Applications" course at the Carlos III University of Madrid. Leganes, Spain, showed that students tend to find it difficult to maintain acceptable motivation levels, which, in many cases, resulted in their ceasing to attend classes and not dedicating enough time to acquire the required competencies. Only 63 out of these 120 students (52.5\%) attended more than half of the classes in the course, and the average grade for those 120 students was only 4.7 out of 10 . Trying to improve the pattern of evolution of student motivation with time was considered essential to improving these results. An experiment based on sending contextualized learning pills (short exercises) to the mobile devices of students attending class was used in the 2010 offering of the course; the results are presented in Section IV. In order to evaluate the time patterns of the motivational state of the students on the course, a questionnaire was taken at three different occasions during the course: at the beginning, toward the middle, and near the end of the course. The questionnaire, evaluated on a Likert-type scale [22] (1-Strongly disagree, 2-Disagree, 3-Neither agree or disagree, 4-Agree, 5-Strongly agree), was kept as simple as possible to maximize the number of responses and consisted of the following questions.

1) Personally, I consider the contents of this course interesting or appealing.

2) The grades I get in this course are very important compared to those for other course I am currently taking

3) The opinion that the professor may have of me is important

4) The contents of this course are important for the type of job I want to get in the future

5) I enjoy using mobile devices for learning

The first question tries to assess the level of intrinsic motivation of students. Questions 2 and 3 are related to a controlled motivational profile, while question 4 assesses the level of autonomous motivation. Question 5 was introduced to evaluate the influence of mobile technology on the motivational state of each student.

A Bluetooth-based environment was designed to send the learning pills to the students in class. The professor created the pills (short exercises) and linked them to the different concepts taught in the course. The students willing to receive the pills used a Web-based application to register their mobile devices' Bluetooth name or Medium Access Control (MAC) address. When in class, the professor used a Java-based application running on a laptop to detect the mobile devices in class registered as willing to receive the pills, and using the Bluetooth Object Exchange (OBEX) service, sent them the pills relevant to the concepts covered in that class. The application tracked the students consuming each pill for a later data analysis. Although the application supported the semantic filtering of pills, which would have made it possible for each student to have received pills most appropriate to his or her profile, the experiment described here sent all the pills to all mobile-registered students so as to decorrelate the semantic improvement of results from the basic use of mobile technology to consume learning pills.

\section{Pill Learning Process}

A total of eight learning pills were used throughout the course, with a maximum of one pill being sent in each class. 
- Replace the XXX in the figure and describe the process:
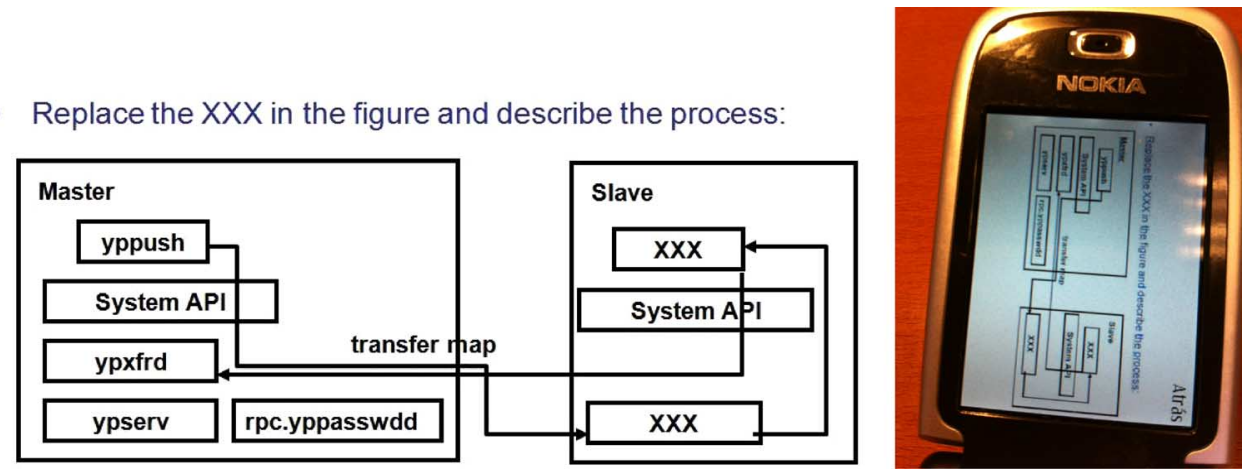

Fig. 1. Example of a learning pill and its appearance on a Nokia 6131 mobile device.

Each learning pill was designed to promote student self-reflection about the main concepts of the course. One pill per class was considered enough to stimulate the study of the contents of that class while not significantly increasing students' workload. Fig. 1 shows an example of a learning pill (translated into English) and its appearance on a Nokia 6131 mobile device (students who participated in the experiment used mobile phones implementing the OBEX service to receive the pills).

The pills, short exercises that had to be solved individually by each student, were sent during class. The students were expected to use them and submit their answer to the professor by e-mail in the $24 \mathrm{~h}$ following the class. The professor reviewed the answers and provided feedback to the students by e-mail so that they could reinforce or redirect the results of their reflection exercise.

Designing the learning pills to be consumed after rather than during the class provided a mechanism to make students dedicate more time to reflecting upon and recapitulating the course contents. Other studies have used clickers [23] or exercises, 1-min papers, and quizzes [24] in class for similar purposes.

\section{EXPERIMENTAL RESULTS}

This section describes the results of the experiment reported here in terms of three main aspects: the improvement of the student class attendance ratio, the levels of student performance, and the quality of student motivational patterns by using mobile devices in class to provide contextualized learning pills.

For the attendance ratio, the previous section stated that only 63 out of the 120 enrolled students $(52.5 \%)$ attended more than half of the classes in the course in the offerings of 2007-2009. The 2010 edition of the course, which used learning pills in class, improved this ratio to $56 \%$ (28 out of 50 ). This is partly related to the fact that the students could only receive the pills in class.

The average grades also improved with the introduction of the pills. Two different analyses were conducted: a comparison of the average student grades in the three offerings without learning pills with the average grades in the offering with pills, and a second comparison that only took into account students who attended more than half of the classes in each case. This distinction is important since nearly half of the students failed to attend classes regularly and were therefore unable to consume the learning pills; it follows that their learning outcomes were influenced little or not at all by the introduction of the pills in class.

The average grade for the 120 students participating in the three offerings from 2007 to 2009 was 4.7 out of 10, while the average grade for the 50 students in 2010 was improved to 5.2 out of 10 . This result, however, is not statistically significant. To analyze the statistical significance of this result, the $t$-test was used, yielding a $p$-value of 0.10 . This being greater than 0.05 means that the null hypothesis cannot be rejected and the difference in grades may be related to random factors. Restricting the analysis to those students attending more than half of the classes, the $p$-value obtained is 0.043 , which is in this case smaller than the 0.05 threshold, and therefore the null hypothesis can be rejected. There is a positive impact on the performance of students attending classes in which the learning pills were available.

There is also a significant difference found between those students who attend more than half of the classes and either do or do not consuming the pills. The average grade for the students attending classes but not consuming the learning pills in the 2010 edition of the course was 4.86 out of 10 , while those consuming the pills had an average grade of 6.49 out of 10 . The $p$-value for the $t$-test in this case is 0.00096 , which is smaller than 0.05 , and therefore the null hypothesis can also be rejected.

The third aspect analyzed is the improvement in student motivational patterns by using mobile devices in class to provide them with contextualized learning pills. The motivational questionnaire described in Section III was used at three different points during the course: at the beginning, toward the middle, and near the end of the course. The difference between students attending classes and consuming the pills and those also attending classes but not consuming the pills will be analyzed in the rest of this section.

Table I shows the mean values of the intrinsic motivation as measured by a questionnaire for both groups of students. The intrinsic motivation of the students follows a common pattern in which the initial motivation is high (related to the enthusiasm at the beginning of the course), but tends to decrease toward the middle of the course (since the effort required to acquire the knowledge and associated skills and attitudes negatively impacts the levels of student motivation), and tends to increase again toward the end of the course (since the effort is somehow compensated by the self-confidence that students acquire when mastering the various parts of the course contents). However, 
TABLE I

INTRINSIC MOTIVATION TIME PATTERNS

\begin{tabular}{lccc}
\hline Learning pills & Initial Q. & Mid-course Q. & Final Q. \\
\hline Non consumers & 4 & 3.17 & 3.33 \\
Consumers & 4.13 & 3.38 & 3.75 \\
\hline
\end{tabular}

TABLE II

COntrolled Motivation Time Patterns

\begin{tabular}{lccc}
\hline Learning pills & Initial Q. & Mid-course Q. & Final Q. \\
\hline Non consumers & 4 & 3.67 & 3.92 \\
Consumers & 4.13 & 4.07 & 4.25 \\
\hline
\end{tabular}

there are some significant differences in the values of intrinsic motivation between those students consuming the learning pills and those who do not. The values are always higher for students consuming the pills. This is related to the fact that those students found the course contents to be more interesting or appealing, and thus tended to make more intensive use of the tools provided to interact with these contents. Another difference in the intrinsic motivation time pattern in both groups of students is that the gap between the motivational values for students consuming the pills and those not consuming them increases as time passes. The initial gap is only 0.13 , the distance at the middle of the course is 0.21 , and the final distance is 0.42 .

Table II shows the results for controlled motivation (taken as an average value from questions 2 and 3 in the questionnaire). Although similar pattern evolutions are observed, two aspects can be underlined. First, the differences both between groups and between questionnaires are smaller than those for intrinsic motivation. Second, the value for controlled motivation in students consuming the pills is even bigger at the end of the course than at the beginning. The impact on students of the external factors driving this type of motivation, such as student grades and the professor's opinion, tends to be less of an influence than intrinsic motivation in the time-frame of a course like this (four months). The fact that the value for the controlled motivation of students consuming the pills is bigger at the end of the course than at the beginning could be explained by the students consuming the pills being more involved in the activities in class and making more effort to consume the pills, therefore the impact of failing the course would be correspondingly bigger for them.

Table III shows the results for the evolution of autonomous motivation as measured by question 4 in the questionnaire. The values do not change significantly as time passes since this type of motivation is the result of a long process of self-reflection and internalization of principles and values experienced by each individual student. The mean values are slightly higher for students consuming the pills.

The positive impact that mobile technologies may have on student motivation because of the enjoyment students derive from them is shown in Table IV. The main conclusion is that students enjoy using mobile devices for learning, and they do
TABLE III

Autonomous Motivation Time PATTERNS

\begin{tabular}{lccc}
\hline Learning pills & Initial Q. & Mid-course Q. & Final Q. \\
\hline Non consumers & 4.33 & 4 & 4.17 \\
Consumers & 4.25 & 4.38 & 4.25 \\
\hline
\end{tabular}

TABLE IV

Technology Influence on Motivation Time PATTERNS

\begin{tabular}{lccc}
\hline Learning pills & Initial Q. & Mid-course Q. & Final Q. \\
\hline Consumers & 4.38 & 4 & 4.65 \\
\hline
\end{tabular}

so even more at the end of the course than at the beginning. As with the course contents, the use of mobile technology is seen as a positive factor at the beginning of the course. Becoming familiar with the technology may take some effort, but once a student has assimilated its use, that student's perception of the use of mobile technology for learning is even better than at the beginning of the course.

\section{CONCLUSION}

This paper has described a successful experiment that was able to improve the ratio of student class attendance, student performance and student motivational patterns for electrical and computer science engineering students by using mobile devices in class to provide them with contextualized learning pills (short exercises). Data collected from 170 students over different offerings of a network services configuration course was used in this study.

The rate of students attending more than half of the classes was slightly improved, by $3.5 \%$, comparing the offering of the course in which the learning pills were used to that in which they were not. The average grades for students attending classes in offerings of the course in which the pills were not used are significantly worse (using statistical significance) than those of students attending classes in which pills were sent. Finally, the use of learning pills has a positive impact on the evolution of the motivational states of the students over the duration of the course. This is especially true for intrinsic motivation, while being less noticeable for external motivation.

Future work will evaluate the use of multimedia (video) pills to summarize the concepts of the course as an addition to the short problems used in this paper.

\section{REFERENCES}

[1] A. Rugarcia, R. M. Felder, D. R. Woods, and J. E. Stice, "The future of engineering education-I: A vision for a new century," Chem. Eng. Educ., vol. 34, no. 1, pp. 16-25, 2000.

[2] A. Holzinger, A. Nischelwitzer, and M. Meisenberger, "Mobile phones as a challenge for m-learning: Examples for Mobile Interactive Learning Objects (MILOs)," in Proc. 3rd IEEE PerCom Workshops, 2005, pp. 307-311.

[3] E. Syukur and S. W. Loke, "MHS learning services for pervasive campus environments," in Proc. 5th IEEE PerCom Workshops, 2007, pp. 204-210. 
[4] H. Ogata, "Computer supported ubiquitous learning: Augmenting learning experiences in the real world," in Proc. 5th IEEE WMUTE, Beijing, China, 2008, pp. 3-10.

[5] T. T. Wu, T. C. Yang, G. J. Hwang, and H. C. Chu, "Conducting situated learning in a context-aware ubiquitous learning environment," in Proc. 5th IEEE WMUTE, Beijing, China, 2008, pp. 82-85.

[6] S. Thomas, "Pervasive, persuasive eLearning: Modeling the pervasive learning space," in Proc. 3rd IEEE PerCom Workshops, 2005, pp. 332-336.

[7] R. Keil-Slawik, T. Hampel, and B. Essmann, "Re-conceptualizing learning environments: A framework for pervasive elearning," in Proc. 3rd IEEE PerCom Workshops, 2005, pp. 322-326.

[8] A. Syvanen, R. Beale, M. Sharples, M. Ahonen, and P. Lonsdale, "Supporting pervasive learning environments: Adaptability and context awareness in mobile learning," in Proc. IEEE WMTE, Tokushima, Japan, 2005, pp. 251-253.

[9] S. Kajita and K. Mase, "uClassroom: Expanding awareness in classroom to ubiquitous teaching and learning," in Proc. 4th IEEE WMUTE, 2006, pp. 161-163.

[10] K. Kim, "Ubiquitous learning supporting system for future classroom in Korea," in Proc. Soc. Inf. Technol. Teacher Educ. Int. Conf., Mar. 2008, pp. 2648-2657.

[11] V. Jones and J. H. Jo, "Ubiquitous learning environment: An adaptive teaching system using ubiquitous technology," in Proc. 21st ASCILITE Conf., Dec. 2004, pp. 468-474.

[12] K. Scott and R. Benlamri, "Context-aware services for smart learning spaces," IEEE Trans. Learn. Technol., vol. 3, no. 3, pp. 214-227, Jul. -Sep. 2010.

[13] P. Nihalani and M. Mayrath, "Mobile learning: Evidence of increased learning and motivation from using an iPhone app," GetYa Learn On, Austin, TX, White Paper, Aug. 2010 [Online]. Available: http://www. getyalearnon.com/WhitePaper_08312010.pdf

[14] K. Swan, M. van't Hooft, A. Kratcoski, and D. Unger, "Uses and effects of mobile computing devices in K-8 classrooms," J. Res. Technol. Educ., vol. 38, no. 1, pp. 99-113, 2005.

[15] N. T. Nghe, P. Janecek, and P. Haddawy, "A comparative analysis of techniques for predicting academic performance," in Proc. IEEE FIE Conf., Milwaukee, WI, 2007, pp. T2G-7-T2G-12.

[16] G. W. Cox, W. E. Hughes, Jr., L. H. Etzkorn, and M. E. Weisskopf, "Predicting computer science Ph.D. completion: A case study," IEEE Trans. Educ., vol. 52, no. 1, pp. 137-143, Feb. 2009.

[17] , J. M. Keller and C. M. Reigeluth, Eds., "Motivational design of instruction," in Instructional Design Theories and Models: An Overview of Their Current Status. Hillsdale, NJ: Erlbaum, 1983.

[18] R. M. Ryan and E. L. Deci, "Intrinsic and extrinsic motivations: Classic definitions and new directions," Contemp. Educ. Psych., vol. 25, no. 1, pp. 54-56, 2000.

[19] R. M. Ryan and E. L. Deci, "Self-determination theory and the facilitation of intrinsic motivation, social development, and well-being," Amer. Psych., vol. 55, pp. 68-78, 2000.

[20] C. F. Ratelle, F. Guay, R. J. Vallerand, S. Larose, and C. Senécal, "Autonomous, controlled, and amotivated types of academic motivation: A person-oriented analysis," J. Educ. Psych., vol. 99, no. 4, pp. 734-746, 2007.

[21] Z. Kovacic and J. Green, "A strategy for reaching students and increasing their motivation," in Proc. Pan Commonwealth Forum, Dunedin, New Zealand, 2004 [Online]. Available: http://www.col.org/ pcf3/Papers/PDFs/Kovacic_\%20Green.pdf

[22] R. Likert, "A technique for the measurement of attitudes," Arch. Psych., vol. 22 , no. 140 , pp. $1-55,1932$.
[23] L. Lugaric, M. Delimar, S. Krajcar, and I. Rajsl, "Real-time student assessment using a system of RF clickers," in Proc. 30th ITI, Jun. 23-26, 2008, pp. 83-88.

[24] J. V. Benlloch-Dualde, F. Buendía, and J. C. Cano, "On the design of interactive classroom environments based on the tablet PC technology," in Proc. 40th ASEE/IEEE Annu. Frontiers Educ. Conf., Arlington, VA, Oct. 27-30, 2010, pp. T4C-1-T4C-6.

Mario Muñoz-Organero (M'08) received the M.Sc. degree in telecommunications engineering from the Polytechnic University of Catalonia, Barcelona, Spain, in 1996, and the Ph.D. degree in telecommunications engineering from the Carlos III University of Madrid, Leganes, Spain, in 2004.

$\mathrm{He}$ is an Associate Professor of telematics engineering at the Carlos III University of Madrid. He has also more than four years of experience working for the telecommunications industry in companies such as Telefonica $R \& D$ and Lucent Technologies, both in Madrid, Spain. His research projects have included topics related to open architectures for e-learning systems, open service creation environments for next-generation networks, advanced mobile communication systems, pervasive computing, and convergent networks. He has participated in several European-funded projects such as E-LANE and Spanish-funded projects such as MOSAIC learning, Learn3 and OSAMI. He currently is the lead researcher of the Spanish-funded ARTEMISA project. His main current interests are e-learning and m-learning technologies.

Pedro J. Muñoz-Merino (M'10) received the M.Sc. degree in telecommunications engineering from the Polytechnic University of Valencia, Valencia, Spain, in 2003, and the Ph.D. degree in telematics engineering from the Universidad Carlos III de Madrid, Leganes, Spain, in 2009.

$\mathrm{He}$ is a Visiting Professor of telematics engineering with the Universidad Carlos III de Madrid. He has participated in approximately 15 research projects and is coauthor of approximately 30 papers in conferences and journals. Currently, his main areas of research include intelligent tutoring systems, learning platforms, interactive learning environments, evaluation of learning experiences, or the semantic Web.

Dr. Muñoz-Merino received the award for the Best Master's Thesis in Telematics Engineering from the Spanish Association of Telecommunications Engineering in 2003 and was given a special Ph.D. award from the Universidad Carlos III de Madrid in 2010.

Carlos Delgado Kloos (M'05-SM'06) received the Ph.D. degree in computer science from the Technical University of Munich, Munich, Germany, and the $\mathrm{Ph} . \mathrm{D}$. degree in telecommunication engineering from the Technical University of Madrid, Madrid, Spain, in 1986.

He is a Full Professor of telematics engineering at the Carlos III University of Madrid, Leganes, Spain, where he was the Founding Director of the Department of Telematics Engineering. He is currently Associate Vice-Chancellor, Director of two Master's programs (one on e-learning), and Director of the Nokia Chair. $\mathrm{He}$ has authored over 200 articles in national and international conferences and journals. He has authored one book, coauthored another, and co-edited five. $\mathrm{He}$ was the Coordinator of the European-funded E-LANE project on e-learning in Latin America and a Member of the Board of Directors of the .LRN Consortium. He has been involved in more than 20 projects with European (Esprit, IST, @LIS), national (Spanish Ministry), and bilateral (Spanish-German and Spanish-French) funding. His main current research interest lies in educational technologies. 